Advances in Cement Research Volume 29 Issue 10

Steady viscous flow of some commercial Andean volcanic Portland cement pastes Páez-Flor, Rubio-Hernández and

Velázquez-Navarro
Advances in Cement Research, 2017, 29(10), 438-449 http://dx.doi.org/10.1680/jadcr.16.00188 Paper 1600188

ite

\title{
Steady viscous flow of some commercial Andean volcanic Portland cement pastes
}

\section{Nicolás Marcelo Páez-Flor}

DECEM, Universidad de las Fuerzas Armadas, Sangolquí, Ecuador

\section{Francisco José Rubio-Hernández}

Departamento de Física Aplicada II, Universidad de Málaga, Málaga, Spain (corresponding author: fjrubio@uma.es)
José Francisco Velázquez-Navarro

Departamento de Ingeniería Mecánica, Térmica y de Fluidos,

Universidad de Málaga, Málaga, Spain

Three commercial Ecuadorian cements, obtained from crushing a mix of clinker and a mixture of pumice powder and volcanic ash, were selected to perform studies on steady viscous flow behaviour. Steady flow curves were obtained during the dormant period. All pastes showed non-linear viscoplastic behaviour. A modified Bingham model was fitted to the experimental data. The yield stress was found to increase and plastic viscosity decreased with clinker substitution. These results were justified by using a model that considers fresh volcanic cement paste as a suspension of particles (cement and volcanic powder) dispersed in a liquid phase, formed by water, and a gel part, formed from the cement-water chemical reaction.

\section{Notation}

$c$

$-\mathrm{d} V_{z} / \mathrm{d} r \quad$ shear rate

$E_{\mathrm{m}} \quad$ pump efficiency

$K \quad$ consistency (Pa.s ${ }^{n}$ )

$l \quad$ length of cylindrical pipe

$n \quad$ flow index

$P_{\mathrm{h}} \quad$ hydraulic power (W)

$P_{l} \quad$ reduced pressure gradient

$p \quad$ hydrostatic pressure

$Q \quad$ volumetric flow rate

$R \quad$ cylindrical pipe radius

$R_{\mathrm{p}} \quad$ cylindrical solid body radius

$r_{\mathrm{M}} \quad$ maximum particle size

$r_{\mathrm{m}} \quad$ minimum particle size

$t_{i} \quad$ time interval

$V_{\mathrm{p}} \quad$ velocity of cylindrical solid body

$\gamma \quad$ shear rate $\left(\mathrm{s}^{-1}\right)$

$\eta \quad$ apparent viscosity (Pa.s)

$\eta_{\mathrm{p}} \quad$ plastic viscosity (Pa.s)

$\tau \quad$ shear stress $(\mathrm{Pa})$

$\tau_{\mathrm{o} i} \quad$ initial shear stress $(\mathrm{Pa})$

$\tau_{r z} \quad$ shear component of extra stress tensor

$\tau_{\mathrm{s} i} \quad$ steady shear stress

$\tau_{\mathrm{w}} \quad$ shear stress on the wall $(\mathrm{Pa})$

$\tau_{\mathrm{y}} \quad$ yield stress $(\mathrm{Pa})$

$\tau_{\Delta}=\tau_{n}-\tau_{\mathrm{oo}}$ difference between maximum and minimum shear stresses $(\mathrm{Pa})$

\section{Introduction}

Concrete is the most commonly used construction material. However, production of the main component of this complex material, Portland cement (PC), accounts for around 5\% of worldwide carbon dioxide emissions. Moreover, the use of PC without any other additions can result in durability problems for structures in aggressive environments. The use of alternative or complementary binders and admixtures in concrete formulations is an effective way of reducing carbon dioxide emissions and also improving the performance of concrete (Horton, 2001; Malhotra, 2010; Popovic, 2001). In addition, the replacement of cement with other binders also allows waste materials to be recycled and optimise the use of natural resources (Meinhold et al., 2001; Uchikawa, 2000). Even through many different concrete binders are used as cement replacements, such as pulverised-fuel ash (Sonebi and Cevik, 2009), rice husk ash (Bui et al., 2005; Chatveera and Lertwattanaruk, 2009, 2011; Giaccio et al., 2007; Memon et al., 2011; Safiuddin et al., 2012; Zerbino et al., 2012), blast-furnace slag (Abdelkader et al., 2010; Dellinghausen et al., 2012), fly ash (McCarthy and Dhir, 1999; Rubio-Hernández et al., 2011; Zhen-Shuang, 2011), limestone filler (Ramezanianpour et al., 2009; Rubio-Hernández et al., 2013a), metakaolin (Khatib, 2008; Sfikas et al., 2014) and alkali-activated binders (geopolymers) (Bernal et al., 2011), new materials are still welcome (Ramezanianpour, 2014).

The replacement of cement with other binders in blended cements can be as high as $60 \mathrm{wt} \%$ (Bilodeau and Malhotra, 2000 ) if the binders show specific pozzolanic activity and good cementitious characteristics (i.e. the reaction rate with calcium hydroxide (lime) in the presence of water is appropriated and improves mechanical strength of the material in the hardened state). One such binder with these properties is volcanic ash (VA), which is a natural pozzolanic powder originating from volcanic eruptions. Natural pozzolanic powders improve the physical (cohesiveness, consolidation, flowability, setting time and strength at later ages) and chemical (durability) parameters of concrete. Moreover, their use reduces carbon dioxide emissions and their recycling is straightforward. The benefits of industrial usage of VA include not only reductions in the cost of cement production but also an increase in the 
Steady viscous flow of some commercial Andean volcanic Portland cement pastes Páez-Flor, Rubio-Hernández and

Velázquez-Navarro use of local labour; consequently, use of this natural resource in developing countries yields both economic and social benefits. Previous studies on Turkish VA and pumice powder (PP) (Hossain, 2003, 2004) have shown that hardened concrete formulated with volcanic Portland cements (VPCs) (i.e. an amount of $\mathrm{PC}$ is replaced by $\mathrm{VA}+\mathrm{PP}$ mixtures) has a higher setting time and a lower heat of hydration. These studies indicated that Turkish VPC is suitable for use in mass concrete construction. In addition, the presence of PP in blended cements inhibits the corrosion of embedded reinforcing steel bars due to densification of the cement paste matrix (Hossain, 2005) and, when the particle size of the PP is small, concrete segregation is appreciably diminished (Ramezanianpour, 2014).

Radiocarbon dating has demonstrated abundant volcanic activity over the last 3000 years in the Andes Mountains. Currently, this geological phenomenon is exemplified by the existence of 20 active volcanoes in Ecuador, with four (Tungurahua, Cotopaxi, Sangay and Reventador) currently in a state of eruption. VA and other volcanic rocks like pumice are thus abundant in this part of the world.

Although VPC concrete has attracted extensive research attention in the hardened state (Hossain, 2003, 2004, 2005; Hossain et al., 2011; Kabay et al., 2015), studies on its behaviour in the fresh state are lacking. As concrete performance in the hardened state significantly depends on its fresh-state behaviour and concrete rheology is a key element in the design of formulations for specific applications (Ferraris, 2005), systematic studies on the behaviour of VPC concrete in the fresh state are certainly necessary.

As a general rule, fresh cementitious materials are nonNewtonian fluids. The viscous response of these materials differs according to the size, the shape and the first chemical reaction of binders. The use of classical 'rheological' methods (Abrams cone, V-funnel etc.) only supplies empirical and semi-quantitative information about the flow behaviour of fresh concrete (Banfill, 2006). Moreover, the results obtained depend on the technique or the instrument used. A great deal of effort has been spent in attempts to obtain accurate and reproducible results on concrete rheology using more or less elaborate concrete rheometers (Wallevik and Gjorv, 1990). However, these methods consume an excessive amount of materials and time. As cement paste rheology controls fresh concrete behaviour (Struble and Sun, 1995) and a systematic rheological characterisation of cement pastes can be easily achieved with the use of absolute rheometers because the maximum cement particle size is noticeably less than the usual gap values required in simple shear rheometric conditions (Macosko, 1994), concrete rheology can be reasonably predicted from a study of cement paste rheology (Farris, 1968; Ferraris and Gaidis, 1992; Flatt, 2004; Hu and De Larrard, 1996; Rubio-Hernández et al., 2013b; Schwartzentruber and Catherine, 2000; Toutou and Roussel, 2006).
A research programme on the rheological behaviour of Andean volcanic concretes has been started. Three commercial Ecuadorian cements were used to conduct a preliminary study on the steady viscous behaviour of fresh VPC pastes, and the results are reported in this paper.

\section{Experimental details}

Three commercial VPCs (Lafarge Cementos S.A., Otavalo, Ecuador) conforming to the Ecuadorian standard INEN 490 (NTE INEN, 2011) were used in this study. These cements, under the commercial names Armaduro, Selvalegre and Campeón, are obtained by crushing a mix of clinker and different amounts of a mixture of PP and VA. X-ray diffraction (PANalytical diffractometer Empyream) was used to obtain the compositions of the VPCs and the PP+VA (Table 1), and the PC and PP+VA amounts in each VPC (Table 2). The main phase in $\mathrm{PC}$, tricalcium silicate $\left(\mathrm{C}_{3} \mathrm{~S}\right)$, was absent in the PP +VA. Andesine - a silicate mineral with pozzolanic activity abundant in the Andes Mountains - was the main component of the PP+VA but was absent in the PC. Therefore, both mineral phases were used as indicators of $\mathrm{PC}$ and $\mathrm{PP}+\mathrm{VA}$ percentage contents in each VPC (Table 2).

Fresh cement pastes can be assumed to be concentrated suspensions of cement particles in water. Therefore, the geometrical characteristics of the solid phase have a determining influence on the flow behaviour of cement paste (RubioHernández et al., 2011). More specifically, the particle shape has a decisive influence on the suspension flow behaviour due to resulting distortions in the flow field. On the other hand, the particle size and specific surface area of the particles have an important effect on the hydration rate because hydration is

Table 1. Chemical composition of PP+VA and VPCS

\begin{tabular}{|c|c|c|c|c|}
\hline & $P P+V A$ & Armaduro & elvalegr & ampeón \\
\hline Andesine: wt\% & 84 & 23 & 36 & 37 \\
\hline Tchermakite: wt\% & 8 & $4 \cdot 6$ & 5 & $6 \cdot 4$ \\
\hline Quartz: wt\% & $3 \cdot 48$ & 1.46 & 1.35 & 0.8 \\
\hline Cordierite: wt\% & $4 \cdot 3$ & $1 \cdot 3$ & 0.7 & $1 \cdot 7$ \\
\hline Tricalcium silicate: wt\% & - & 51.8 & $42 \cdot 7$ & $40 \cdot 2$ \\
\hline Dicalcium silicate: wt\% & - & $6 \cdot 4$ & $5 \cdot 5$ & 4.9 \\
\hline $\begin{array}{l}\text { Tetracalcium aluminate } \\
\text { ferrite: } w t \%\end{array}$ & - & $3 \cdot 3$ & $3 \cdot 1$ & $2 \cdot 5$ \\
\hline $\begin{array}{l}\text { Tricalcium } \\
\text { aluminate: wt\% }\end{array}$ & - & $5 \cdot 2$ & $4 \cdot 4$ & $3 \cdot 8$ \\
\hline Gypsum: wt\% & - & $2 \cdot 7$ & 1.7 & $2 \cdot 2$ \\
\hline
\end{tabular}

Table 2. Contents of Portland cement (PC), volcanic pumice powder (PP) and volcanic ash (VA) in VPCs (calculated from tricalcium silicate and andesine amounts shown in Table 1)

\begin{tabular}{|lcc|}
\hline VPC & PC: $\mathbf{w t} \%$ & PP+VA: wt\% \\
\hline Armaduro & $69 \cdot 4$ & $30 \cdot 6$ \\
Selvalegre & $57 \cdot 4$ & $42 \cdot 6$ \\
Campeón & $53 \cdot 6$ & $46 \cdot 4$ \\
\hline
\end{tabular}


much faster for smaller particles. Consequently, information on particle shape, size and specific surface area are necessary in order to properly analyse the rheology of fresh cement pastes. According to information supplied by the manufacturer, the industrial process used to obtain the three commercial VPCs used in this study consists of the simultaneous grinding and sieving of three different preset mixtures of clinker, gypsum and PP+VA powder, using the same mechanical device.

Scanning electron microscopy (SEM) (JSM-6490LV, Jeol Ltd, Tokyo, Japan) of the VPC revealed that individual VPC particles showed a similar variety of angular shapes in all cases (Figure 1) - on other words, no significant differences in particle shape were observed. In order to obtain the particle size distribution, the SEM micrographs were processed using toolbox routines included in Matlab software (MathWorks Inc., Natick, MA, USA). The mean particle size (29-32 $\mu \mathrm{m})$ was determined to be approximately the same for all the VPCs (Figure 2). The polydispersity index was calculated according to the method described by Masoero et al. (2012). It was quantified using the standard deviation of the initial size distribution in units of $\left(r_{\mathrm{M}}+r_{\mathrm{m}}\right) / 2$, where $r_{\mathrm{M}}$ and $r_{\mathrm{m}}$ are the maximum and minimum particle sizes, respectively. The results were similar for the three VPCs $(\approx 15 \cdot 5)$. The specific surface area was measured using a Quantachrome Nove 2000 instrument using the BET (Brunauer, Emmett and Teller) method. The results indicated only slight variations between the three VPCs, with values in the range $2 \cdot 2-2 \cdot 6 \mathrm{~m}^{2} / \mathrm{g}$.

Erratic results due to the dependency of the rheological parameters on mixing methods must be avoided (Han and Ferron, 2015) and a pre-designed protocol for sample preparation should thus be defined. In this work, distilled water (Merck Milli-Q Integral, Malvern, UK) was slowly added to the powder and mixed for $120 \mathrm{~s}$ at $75 \mathrm{rpm}$ in an RZR1 mixer (Heidolph Instruments, Germany). The water/binder ratio was fixed at $0 \cdot 45$.

A stress-controlled rheometer (Haake RS600, Thermo Scientific Instruments, Germany) was used to collect rheological data. The device was equipped with a water circulatory system (Haake DC30, Thermo Scientific Instruments, Germany) for temperature control, and each experiment was conducted on fresh samples at $25 \cdot 00 \pm 0 \cdot 05^{\circ} \mathrm{C}$. Following current recommendations for rheological tests on cementitious materials, preliminary measurements were performed using the vane-in-cup method (cup, $55 \mathrm{~mm}$ high and $28 \mathrm{~mm}$ diameter; vane, $41 \mathrm{~mm}$ high and $25 \mathrm{~mm}$ diameter). The results indicated an increase in viscosity after certain period of time (and also an absence of reproducibility). Moreover, after finishing the rheological tests, sedimentation of the paste at the bottom of the cup was visually observed. As the replacement of cement with other binders can reduce the segregation resistance of fresh pastes (Ramezanianpour, 2014), this unexpected experimental inconvenience with the use of the vane-in-cup method could be justified. A plate-plate geometry was then used for
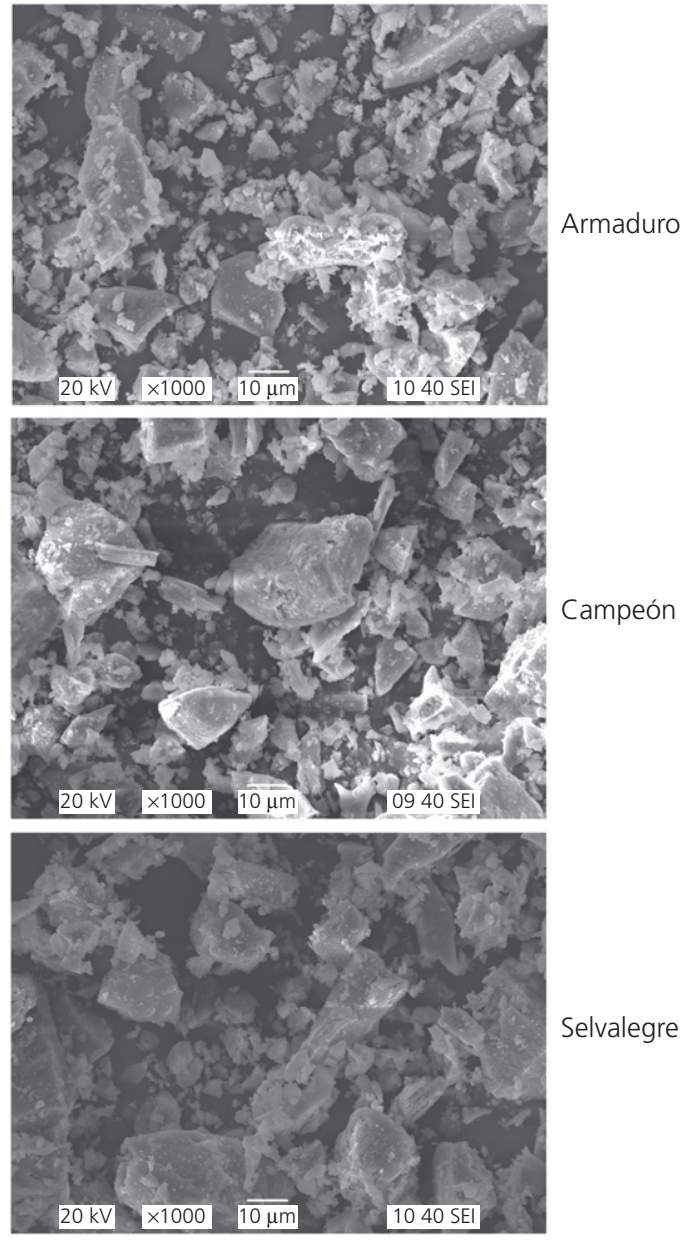

Figure 1. SEM images of VPC particles

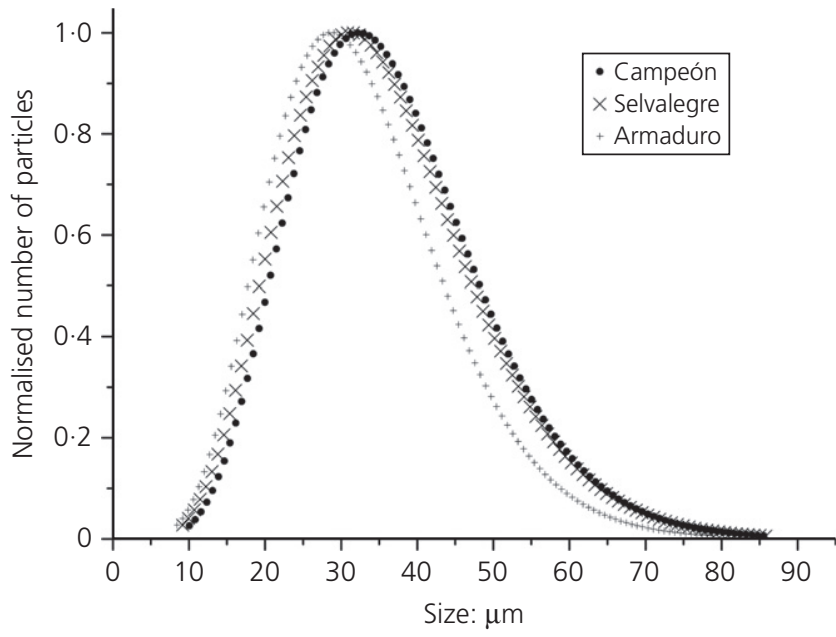

Figure 2. Size distribution of VPC particles obtained from SEM images using toolbox routine included in Matlab software; mean values $(29-32 \mu \mathrm{m})$ were obtained from analysis of SEM images 
Steady viscous flow of some commercial Andean volcanic Portland cement pastes Páez-Flor, Rubio-Hernández and Velázquez-Navarro

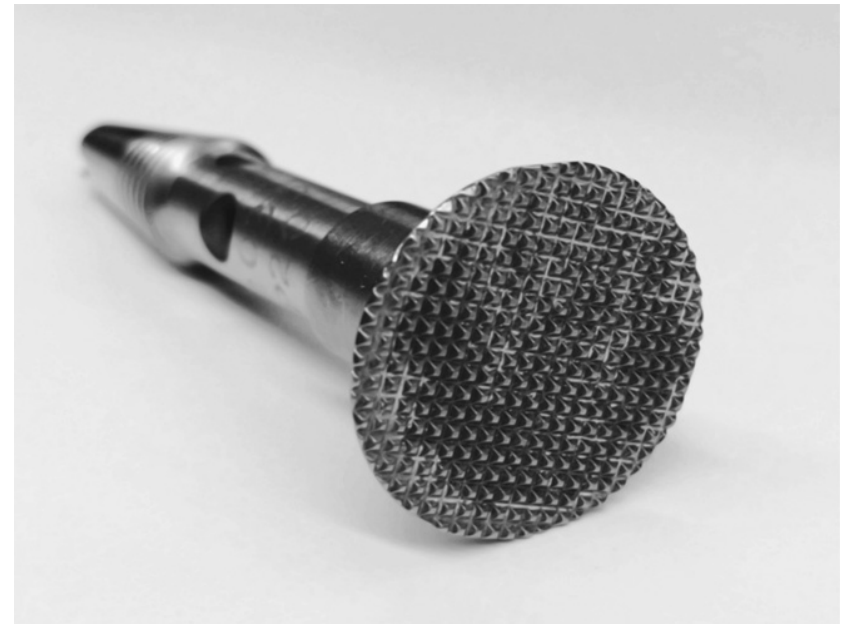

Figure 3. Detail of the serrated plate geometry used in this study

rheological studies in order to minimise sedimentation of the pastes. However, as some sedimentation was presumably present despite the small gap between the plates $(1 \mathrm{~mm})$, a serrated geometry (Figure 3) was used to avoid slippage of the top plate resulting from the eventual lower particle concentration in the portion of the sample near the top plate. The non-slippage condition was checked with the serrated plate-plate geometry with the use of three different gaps (1, 1.5 and $2 \mathrm{~mm}$ ). No significant differences in the results were noted and it was thus concluded that slippage was effectively avoided. Viscosity values did not vary after the transitory phase, confirming that sedimentation effects were negligible.

Binder hydration is initiated just after the first contact with water (Paya et al., 2001) and can be described as a sigmoid evolution of hydration heat over the course of time. Five stages of hydration are typically observed: $(a)$ early hydration during about the first $15 \mathrm{~min}$; $(b)$ an induction or dormant stage that can extend until $5 \mathrm{~h}$ after the first cementwater (or PP+VA-water) contact; (c) stability and acceleration stages that finish approximately $8 \mathrm{~h}$ after the start of hydration; (d) slowdown and tightening, which lasts $24 \mathrm{~h}$; (e) setting, which typically finishes $28 \mathrm{~d}$ later. During the early hydration stage a gel phase is rapidly created. This gel phase is formed by products of the cement-water chemical reaction, which are dispersed in the surplus water (Paya et al., 2001). In the dormant period (the second stage of cement hydration) the formation of the gel phase is slow enough to be considered negligible. Therefore, feasible rheological measurements can be made during this dormant period because the chemical composition of the sample can be assumed constant. However, care must be taken during rheological tests because slow cement and/or pumice hydrations certainly occur during the dormant period if the sample is at rest.
To diminish the effect of hydration at rest on the rheological measurements, steady flow curves were designed in down mode (i.e. shear rate values were applied in decreasing sequence). A pre-shear phase $\left(\dot{\gamma}=100 \mathrm{~s}^{-1}\right)$ was first applied until a dynamic steady state was achieved. Different shear times were necessary to reach the equilibrium state in the pre-shear phase when different samples were tested. These experimental conditions were previously evaluated with the three cements and a small range of values was obtained (20-30 s). In order to use the same protocol for rheological studies, a maximum shear time was used in all cases (30 s), in this way ensuring that all the samples achieved a steady state in the pre-shear phase. With the application of pre-shear, random or hazardous initial sample states caused by the positioning of the sample on the rheometer geometry were also erased. The coincidence of steady shear stress values recorded during the pre-shear phase was taken as an indication that the same initial state was achieved before starting the steady flow curve test. Each shear rate of the down curve was applied long enough to ensure a steady state was reached. This condition was accomplished when the relative variation of the shear stress recorded for each shear rate value was less than $4 \%$ over $10 \mathrm{~s}$. The steady flow curve was obtained by plotting the steady shear stress against the corresponding shear rate value. In addition, to confirm that the $\mathrm{PC}$ and/or $\mathrm{PP}+\mathrm{VA}$ dormant periods were not exceeded, a constant post-shear rate $\left(\dot{\gamma}=100 \mathrm{~s}^{-1}\right)$ was applied after the steady flow curve was finished. In all cases, the differences between steady shear stresses corresponding to pre- and post-shear phases coincided with a maximum dispersion of $10 \%$; therefore, hydration effects were assumed negligible during the rheological study. It is worthy of note that samples were maintained in the dormant period when rheological tests were performed. The time interval from the end of mixing to the start of rheological testing was around $480 \mathrm{~s}$. Thus, the rheological tests were started around $10 \mathrm{~min}$ after the first cement-water contact (when the induction period was presumably finished). The length of time needed for the flow curve was around $360 \mathrm{~s}$ (the shear time for the lower shear rate was $60 \mathrm{~s}$, and the time necessary to achieve the steady state was lower when the shear rate increased), with pre- and post-shear phases lasting a further $30 \mathrm{~s}$. Therefore, the total time from the first cement-water contact to the end of the rheological test (three measurements on the same sample were made) was mixing $(120 \mathrm{~s})+$ sample placement on the rheometer $(480 \mathrm{~s})+$ pre-shear $(30 \mathrm{~s})+$ first steady flow curve $(360 \mathrm{~s})+$ post-shear $(30 \mathrm{~s})+$ pre-shear $(30 \mathrm{~s})+$ second steady flow curve $(360 \mathrm{~s})+$ post-shear $(30 \mathrm{~s})+$ pre-shear $(30 \mathrm{~s})+$ third steady flow curve $(360 \mathrm{~s})+$ post-shear ( $30 \mathrm{~s})=1860 \mathrm{~s}$. In other words, the age of the paste at the end of each test was around $31 \mathrm{~min}$, which was less than the limit of the dormant period.

Three fresh samples made with the same cement were tested and each was tested three times. Therefore, nine data sets were averaged to plot the experimental data. 


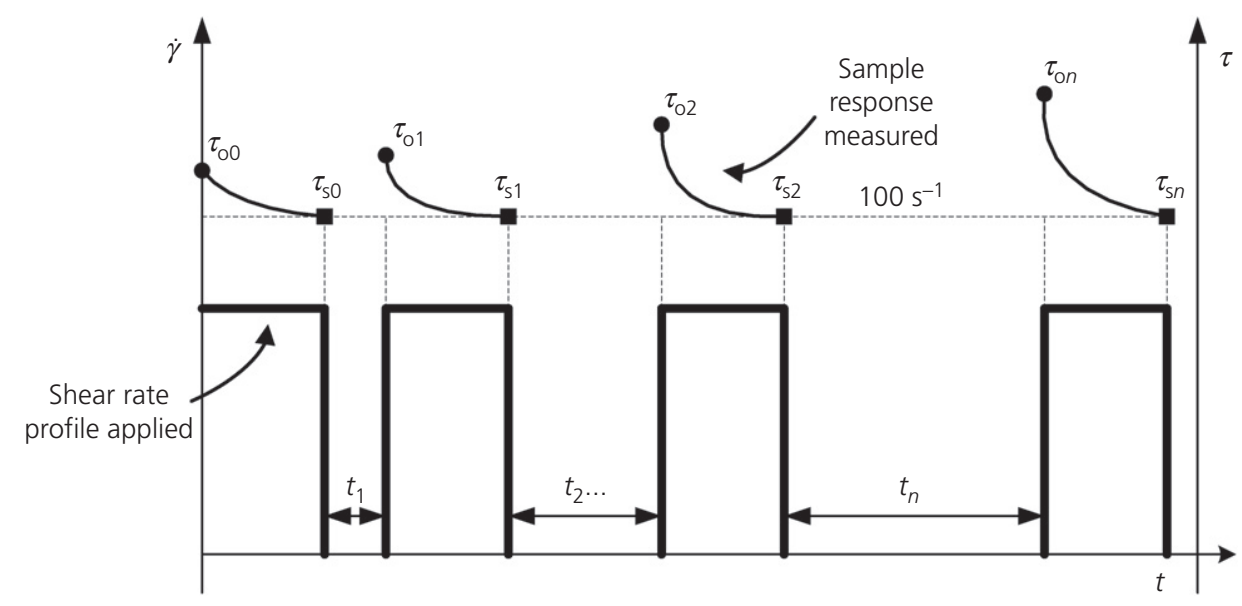

Figure 4. Rheological test for the determination of the maximum achieved-at-rest microstructure

\section{Results and discussion}

The microstructure of a cement paste will be reversible whenever colloidal interactions outweigh hydration effects. The maximum time interval when cement pastes can be considered colloidal suspensions (i.e. disregarding irreversible hydration effects) can be estimated by recording the rest time needed to achieve the maximum reversible microstructure. When cement pastes are at rest, colloidal interactions became stronger and hydration effects speed up, generating linkages among particles (calcium silicate hydrate ( $\mathrm{CSH}$ ) bridges). To determine the maximum rest time that a sample could maintain reversibility conditions, the following rheological test was designed. After resting for increasing time intervals $\left(t_{i}, i=0, \ldots, n\right)$, a constant shear rate $\left(100 \mathrm{~s}^{-1}\right)$ was applied to cement pastes (Figure 4). The initial stress value $\left(\tau_{\mathrm{o} i}, i=0, \ldots, n\right)$ just after applying the shear rate was taken as a quantitative measurement of the microstructural strength achieved during rest time $t_{i}$. The coincidence of steady shear stress values $\left(\tau_{s i}, i=0, \ldots, n\right)$ was used as an indication that the achieved-at-rest process of the microstructure actually started from the same initial state. It is worth noting that this test also supplied information of practical interest. The rate at which the maximum at-rest microstructure was achieved can be used as a measure of sample workability. In other words, cementitious materials that require longer rest times to achieve the maximum microstructure can be used in the fresh state for a much longer time. According to this idea, the rest time dependency of the initial shear stress $\left(\tau_{\mathrm{o} i}\right)$ of fresh VPC pastes was plotted. While other researchers have reported a linear increase of $\tau_{\mathrm{o} i}$ with $t_{i}$ (Roussel, 2006; Roussel et al., 2012), the results obtained in this study fitted exponential growth curves (Figure 5) according to

1. $\tau_{\mathrm{o} i}=\tau_{n}-\tau_{\Delta} \exp \left(-k t_{i}\right)$

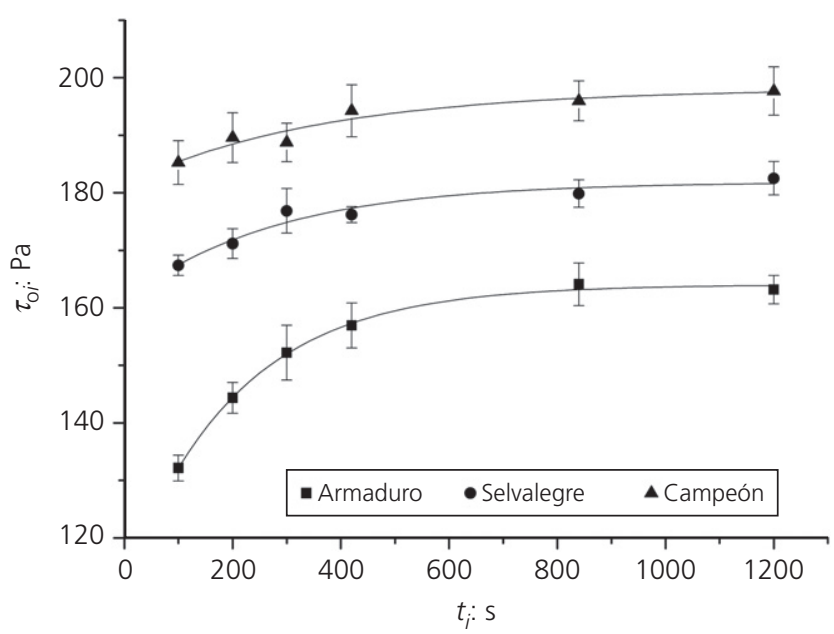

Figure 5. Initial shear stress plotted against rest time after applying a constant shear rate $\left(50 \mathrm{~s}^{-1}\right)$

The fact that the achieved-at-rest microstructure reached the maximum value was an indication that cement hydration effects were not significant, at least during the corresponding rest time, and therefore the VPC pastes could be treated as colloidal suspensions in that time interval. In the analysis described by Roussel (2006) and Roussel et al. (2012), cement hydration that leads to an unlimited irreversible increase of the at-rest microstructure is not separated from reversible colloidal interactions between cement particles. When water and cement particles come into contact, the gel-formation phase starts and, according to linkage theory, cement particles link, acting on the gel as 'glue'. Shear breaks these links and when the deformation ceases the gel phase increases again because the cement-water reaction is favoured and particles approach close to the position of minimum repulsive energy. The 
Steady viscous flow of some commercial Andean volcanic Portland cement pastes Páez-Flor, Rubio-Hernández and Velázquez-Navarro
Table 3. Exponential growth parameters of initial shear stress $\left(\tau_{\mathrm{o} i}\right)$ as a measure of reversible achieved-at-rest microstructure strength in fresh VPC pastes

\begin{tabular}{|lccc|}
\hline VPC & $\boldsymbol{\tau}_{\boldsymbol{n}}: \mathbf{P a}$ & $\boldsymbol{\tau}_{\boldsymbol{\Delta}}: \mathbf{P a}$ & $\boldsymbol{k : ~ s}^{\mathbf{- 1}}$ \\
\hline Campeón & $198 \pm 2$ & $16 \pm 3$ & $0.003 \pm 0.001$ \\
Selvalegre & $181 \pm 2$ & $20 \pm 3$ & $0.004 \pm 0.001$ \\
Armaduro & $164 \pm 1$ & $52 \pm 2$ & $0.005 \pm 0.001$ \\
\hline
\end{tabular}

coincidence (only variations less than $10 \%$ were accepted) of steady stress values $\operatorname{pre}-\operatorname{shear}\left(\tau_{\mathrm{si}}\right)$ and $\operatorname{post-shear}\left(\tau_{\mathrm{si}+1}\right)$ confirms that the sample maintains the same physical and chemical states during testing.

It was observed (Figure 5) that $\tau_{\mathrm{o} i}$ started from a minimum value $\left(\tau_{\mathrm{o} 0}=\tau_{n}-\tau_{\Delta}\right)$ corresponding to the achieved-at-rest microstructure just after application of the pre-shear and in the absence of a previous rest time $\left(t_{0}=0\right) . \tau_{\mathrm{o} i}$ increased up to a maximum value $\left(\tau_{n}\right)$ corresponding to the maximum structure that the cement paste could reversibly achieve at-rest $\left(t_{n}\right)$. Inspection of Figure 5 reveals that $\tau_{n}$ increased with PP+VA content. Results from fitting Equation 1 to the data in Figure $5\left(r^{2}>0.9543\right)$ are shown in Table 3. The precision level of the data shown in Table 3 results from the fitting procedure and, consequently, expresses the level of correlation between the experimental data and the proposed exponential equation.

The VPC with the highest PC substitution (Campeón) developed the strongest maximum microstructure. This can be explained as follows. PP+VA particles did not react with water during the dormant period and could be treated as solid particles dispersed in a liquid (gel+water) medium. A higher $\mathrm{PP}+\mathrm{VA}$ concentration (Campeón) should thus give rise to the strongest microstructure, as was observed. On the other hand, the highest $\tau_{\Delta}$ value observed in the VPC with the lowest PC substitution (Armaduro) can be explained as follows. $\tau_{\Delta}=\tau_{n}-\tau_{\mathrm{o} 0}$ is the difference between maximum and minimum shear stresses (maximum and minimum achieved-at-rest microstructures). The gel formation, a product of the cement-water chemical reaction, was highest for the VPC with the greatest amount of PC; that is, it followed the sequence Armaduro $>$ Selvalegre $>$ Campeón. In other words, the reactivity with water of Armaduro was the highest and, consequently, the greater change in microstructure was observed.

The steady flow curve can be considered as the fingerprint of flowing materials. In the case of cementitious materials, the steady flow curve gives information about flowability and segregation resistance. Steady flow curves of fresh VPC pastes were obtained. All materials were viscoplastic (Figure 6). This is a common behaviour of cementitious slurries; that is, these materials only flow when a threshold stress value or yield stress

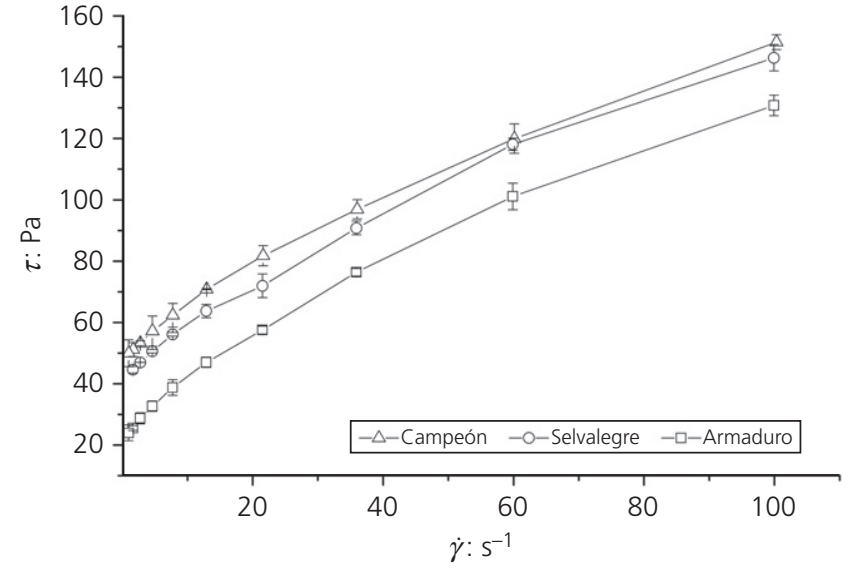

Figure 6. Steady flow curves of VPC pastes. Non-linear viscoplastic behaviour was observed in all cases. The yield stress decreased with an increase in PP+VA concentration

is surpassed. Below this limit, they show solid-like behaviour (i.e. they do not flow but deform elastically). It was observed that the shear stress increased when the PC substitution by PP +VA increased, whatever the shear rate. In other words, the apparent viscosity $(\eta=\tau / \dot{\gamma})$ increased in the sequence Campeón $>$ Selvalegre $>$ Armaduro. As non-linear viscoplastic behaviour was observed in all cases, non-linear equations should be used for fitting the experimental results (modified Bingham, Hershel-Bulkley, Casson etc.). The modified Bingham equation was used to fit the experimental data shown in Figure 6 because a good correlation was observed $\left(r^{2}>0.9987\right)$ and a physical interpretation of the model parameters could be given (Feys et al., 2007)

2. $\tau=\tau_{\mathrm{y}}+\eta_{\mathrm{p}} \dot{\gamma}+c \dot{\gamma}^{2}$

where $\tau_{\mathrm{y}}$ is the yield stress (in Pa), $\eta_{\mathrm{p}}$ is the plastic viscosity (Pa.s) and $c\left(\mathrm{~Pa}_{\mathrm{s}} \mathrm{s}^{2}\right)$ describes the non-linear flow behaviour (i.e. shear thinning when $c / \eta_{\mathrm{p}}<0$ and shear thickening when $\left.c / \eta_{\mathrm{p}}>0\right)$. Equation 2 was used to fit the average of nine experimental data points obtained with each of the three cement pastes. Other authors (Feys et al., 2007; Yahia and Khayat, 2001) have checked the validity of this equation for cementitious materials. The parameter $c$ represents non-linearity of the viscoplastic behaviour. In this work, it was observed that an increase in the amount of cement replaced by VA+PP binder slightly diminished the non-linearity of the viscoplastic behaviour. Moreover, the sign of the parameter $c$ corresponds to enhanced shear-thinning $(c<0)$ or shear thickening $(c>0)$ behaviour. The presence of VA+PP in VPC resulted in enhanced shear-thinning behaviour. It is worth noting that the widely used Herschel-Bulkley equation

3. $\tau=\tau_{\mathrm{y}}+K \dot{\gamma}^{n}$ 
Table 4. Modified Bingham model parameters of fresh VPC pastes

\begin{tabular}{|lccc|}
\hline VPC & $\tau_{\mathbf{y}}:$ Pa & $\eta_{\mathbf{p}}:$ Pa.s & $-\frac{c}{\eta_{\mathbf{p}}}: \mathbf{s}$ \\
\hline Armaduro & $24.9 \pm 0.3$ & $1.64 \pm 0.01$ & $0.0035 \pm 0.0001$ \\
Selvalegre & $43.2 \pm 0.2$ & $1.53 \pm 0.01$ & $0.0032 \pm 0.0001$ \\
Campeón & $50.5 \pm 0.5$ & $1.47 \pm 0.01$ & $0.0031 \pm 0.0001$ \\
\hline
\end{tabular}

contains the parameter $K$ (consistency), which has 'strange' units $\left(\mathrm{Pa} . \mathrm{s}^{n}, n \in \mathbb{R}\right)$. As the flow index $n$ is generally different for different materials, consistencies between different materials cannot be compared (Feys et al., 2007; Rubio-Hernández et al., 2013a). Despite this, sometimes Equation 3 is, surprisingly in the authors' opinion, used to compare the viscous flow behaviour of different materials.

Table 4 shows modified Bingham model parameters corresponding to each VPC. The precision level of the data shown in Table 4 results from the fitting procedure and, consequently, expresses the level of correlation between the experimental data and the modified Bingham model. As can be seen, the VPC paste with the higher amount of PP+VA binder (Campeón) exhibited the highest yield stress value and the lowest values of plastic viscosity and $c / \eta_{\mathrm{p}}$. As described earlier, the VPCs are obtained by crushing a mix of clinker and different amounts of a mixture of PP and VA; therefore, the PC and $\mathrm{PP}+\mathrm{VA}$ particle sizes are similar $(29-32 \mu \mathrm{m})$. The relatively large particles of $\mathrm{PP}+\mathrm{VA}$ are dispersed in a water+gel phase, which induces a high distortion of the flow field when pastes are forced to flow and the gel structure strength is reduced when the amount of PP+VA increases. Consequently, the plastic viscosity decreased when the PC substitution increased; that is, the resistance against segregation of Campeón was lower than that of Armaduro. On the other hand, the yield stress increased with PC substitution due to the larger amount of $\mathrm{PP}+\mathrm{VA}$ particles dispersed in the water+gel phase, giving the lowest flowability for Campeón. Finally, it was finally observed that the variation in $\mathrm{PP}+\mathrm{VA}$ concentration was not enough to produce significant changes in the non-linear response of the VPC pastes. The consequences of the influence of VPC composition on the modified Bingham parameter values is illustrated in the Appendix.

The results obtained from the steady flow curve (Figure 6) and the rest time dependence of the microstructure strength (Figure 5) revealed that a higher PP+VA content (i.e. greater PC substitution) provided a higher apparent viscosity $(\eta)$ but a lower plastic viscosity $\left(\eta_{\mathrm{p}}\right)$. This apparently contradictory result can be explained by assuming the coexistence of three phases just after the first cement-water contact. The three phases are water+gel (which plays the role of the carrier fluid), $\mathrm{PP}+\mathrm{VA}$ particles (which react with water more slowly than the PC particles) and PC particles. As mentioned earlier, there were only small differences in the size, shape and specific surface area of the VPCs. After the end of the first hydration stage and during the lag or dormant phase, gel slowly forms from the fast-reacting PC particles and the slower reacting PP+VA particles (Langan et al., 2002). Therefore, internal friction in VPC pastes with higher PP+VA content should be higher because the last solid components remain unreacted with the water for a longer time than the PC particles. During the dormant period, tricalcium silicate $\left(\mathrm{C}_{3} \mathrm{~S}\right)$ and dicalcium silicate $\left(\mathrm{C}_{2} \mathrm{~S}\right)$, which are major compounds of $\mathrm{PC}$ pastes, generate $\mathrm{CSH}$ as a hydration product, which, with calcium sulfoaluminate (another product from the hydration of PC), leads to the formation of a gel layer surrounding each particle. This layer grows slowly until the water phase becomes supersaturated with gel and the dormant period ends. The at-rest microstructure formation is then due to the coexistence of two mechanisms: particle-particle colloidal interactions and links among particles developed by CSH bridges (Roussel et al., 2012; Sujata and Jennings, 1992). When shear is applied, the $\mathrm{CSH}$ bridges and colloidal links break in a quasi-reversible way. A greater PC replacement by PP+VA particles should give rise to a softer water+gel phase because the gel is mainly generated from the PC hydration. As a consequence, the highest sedimentation of sand and gravel in concrete should be expected when Campeón is used to make the paste because this VPC has the greatest amount of PC substituted by PP+VA particles. To confirm the validity of this prediction, which is consistent with the plastic viscosity values of the VPC pastes (Table 4), cylindrical specimens of mortars were made following the ASTM C 31 (ASTM, 2015). The specimens, with small inert coarse particles ( $1 \mathrm{~mm}$ diameter) suspended in the VPC pastes, were cut along the axial plane after curing for $7 \mathrm{~d}$. To facilitate distinction of the coarse particles with respect to the grey cement paste for imaging analysis, white gravel was used.

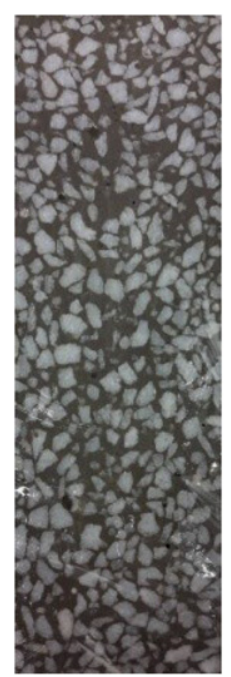

Armaduro

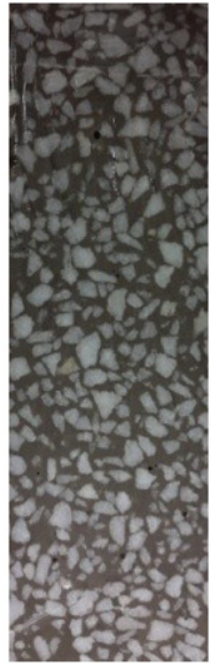

Selvalegre

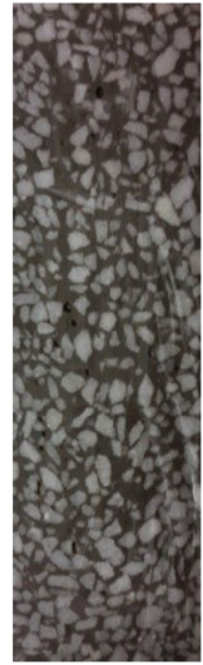

Campeón
Figure 7. Cylindrical specimens cut along axial plane. Photographs were digitalised with the Matlab image processing toolbox 
Steady viscous flow of some commercial Andean volcanic Portland cement pastes Páez-Flor, Rubio-Hernández and Velázquez-Navarro

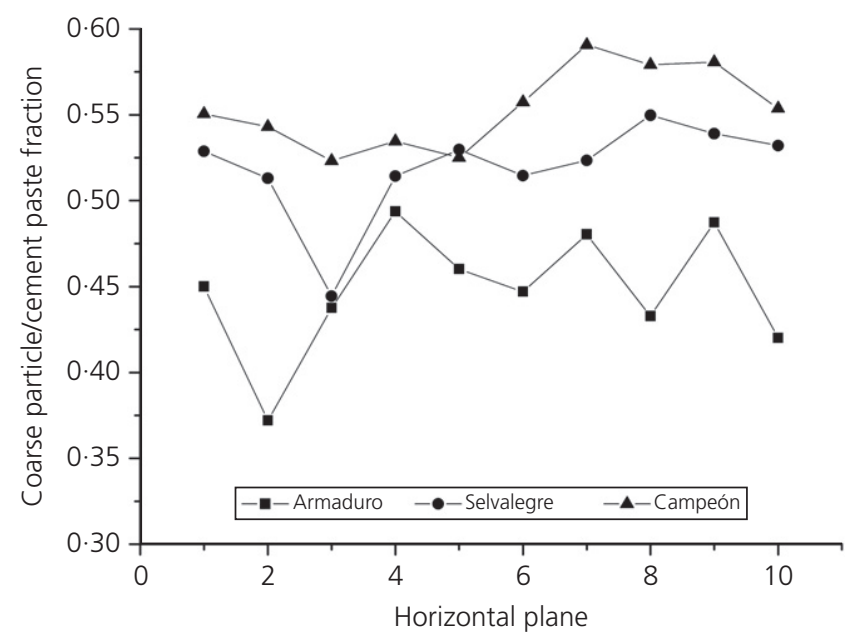

Figure 8. Coarse particle/cement paste fraction corresponding to ten horizontal planes of the cylindrical specimens shown in Figure 7; plane 10 was at the bottom of the cylinder, while plane 0 was the upper cylinder surface

As visual differences between photographs (Figure 7) were not evident with the naked eye, a Matlab image processing toolbox was used to view the distribution along the vertical axis. As shown in Figure 8, a higher concentration of coarse particles was seen in all the selected horizontal sections for a higher content of PP+VA content in the VPC, which confirms the prediction based on the plastic viscosity dependence with $\mathrm{PP}+\mathrm{VA}$ content - that is, the VPC with the higher PP+VA content (Campeón) will show less capacity to avoid coarse particle sedimentation. It was not necessary to match the density of the coarse particles to the pastes because only the relative capacity of the VPC pastes to avoid sedimentation was considered.

\section{Conclusions}

The viscous flow behaviour of three fresh commercial VPCs was examined. Rest time and steady flow curves were used to obtain information on the static and dynamic behaviour. Assuming that the fresh volcanic cement paste is a suspension of cement and volcanic powder dispersed in a water +gel liquid phase, several conclusions of practical interest were obtained.

The rest time curves showed that the microstructural strength of the samples achieved at-rest grew in an exponential way. This result indicates the absence of hydration processes, giving advantages in terms of the increased workability time. With increasing cement substitution with VA+PP binder (Campeón $>$ Selvalegre $>$ Armaduro), faster microstructureat-rest development was observed. This is also a relevant result from a practical point of view, because extra effort will be required when the rest periods of fresh materials are excessively long time.
The steady flow curve results suggest that lower flowability and segregation resistance of the fresh VPC paste occur with a higher cement substitution by volcanic powder. These two factors are important in cement placing and workability tasks, and should be evaluated by taking into account cost-benefits and possible changes in the size particle distribution and the specific surface area of $\mathrm{VA}+\mathrm{PP}$ in order to find appropriate admixtures for specific applications. An increase in viscosity (lower flowability) requires more energy to place fresh cement materials and lower segregation resistance requires extra time for vibration processes or the necessity of adding expensive plasticisers.

\section{Acknowledgement}

The first author expresses his gratitude for a pre-doctoral grant received from ESPE (Ecuador).

\section{Appendix}

Consider the axisymmetric, laminar and steady flow of cement paste through a cylindrical pipe of radius $R$ and length $l$ (Figure 9). A force balance applied to the fluid element shown in Figure 9 gives

4. $p\left(\pi r^{2}\right)-(p+\Delta p) \pi r^{2}=\tau_{r z} 2 \pi r l$

Solving for the shear component $\left(\tau_{r z}\right)$ of the extra stress tensor gives

5. $\tau_{r z}=\left(-\frac{\Delta p}{l}\right) \frac{r}{2}$

A viscoplastic fluid only flows when the applied stress (due to a pump) is greater than the yield stress $\left(\tau_{\mathrm{y}}\right)$. Therefore, near the axis, where the shear stress is lower than the yield stress (Figure 10) the cement paste moves as a cylindrical solid body. The radius of this cylindrical solid body $\left(R_{\mathrm{p}}\right)$ is related to the yield stress and the shear stress on the wall $\left(\tau_{\mathrm{w}}\right)$ as (Chhabra and Richardson, 1999)

6. $R_{\mathrm{p}}=R \frac{\tau_{\mathrm{y}}}{\tau_{\mathrm{w}}}$

The shear stress on the wall is related to the pressure gradient by

7. $\tau_{\mathrm{w}}=\left(-\frac{\Delta p}{l}\right) \frac{R}{2}$

Substituting Equation 7 in Equation 6, the value of $R_{\mathrm{p}}$ is obtained as a function of known magnitudes

8. $\quad R_{\mathrm{p}}=2 \frac{\tau_{\mathrm{y}}}{(-\Delta p / l)}$ 


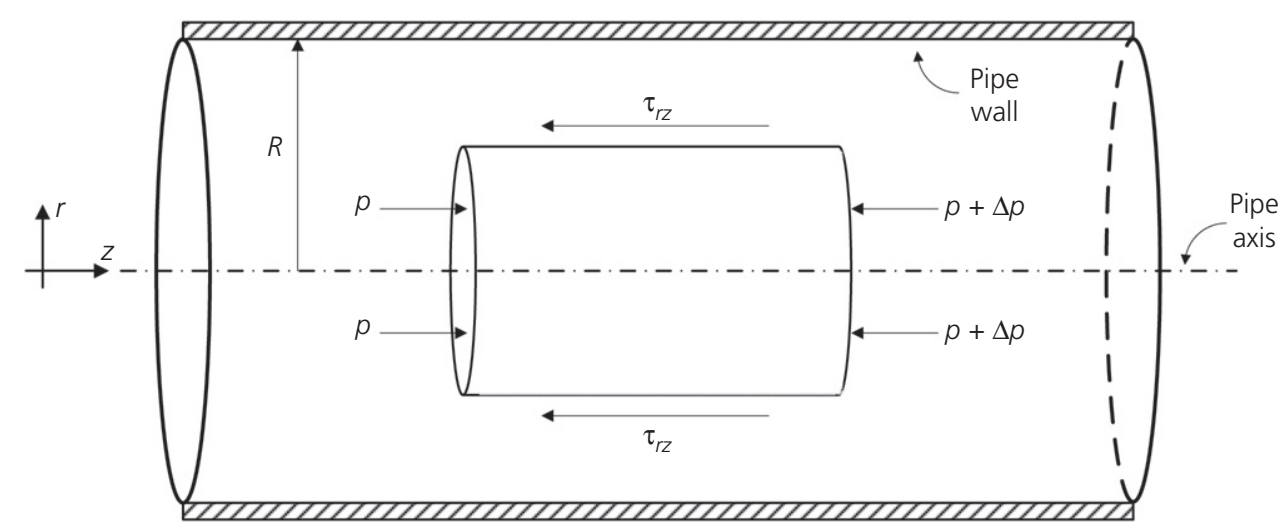

Figure 9. Axisymmetric, laminar and steady flow of a fluid through a cylindrical pipe of radius $R$ and length /

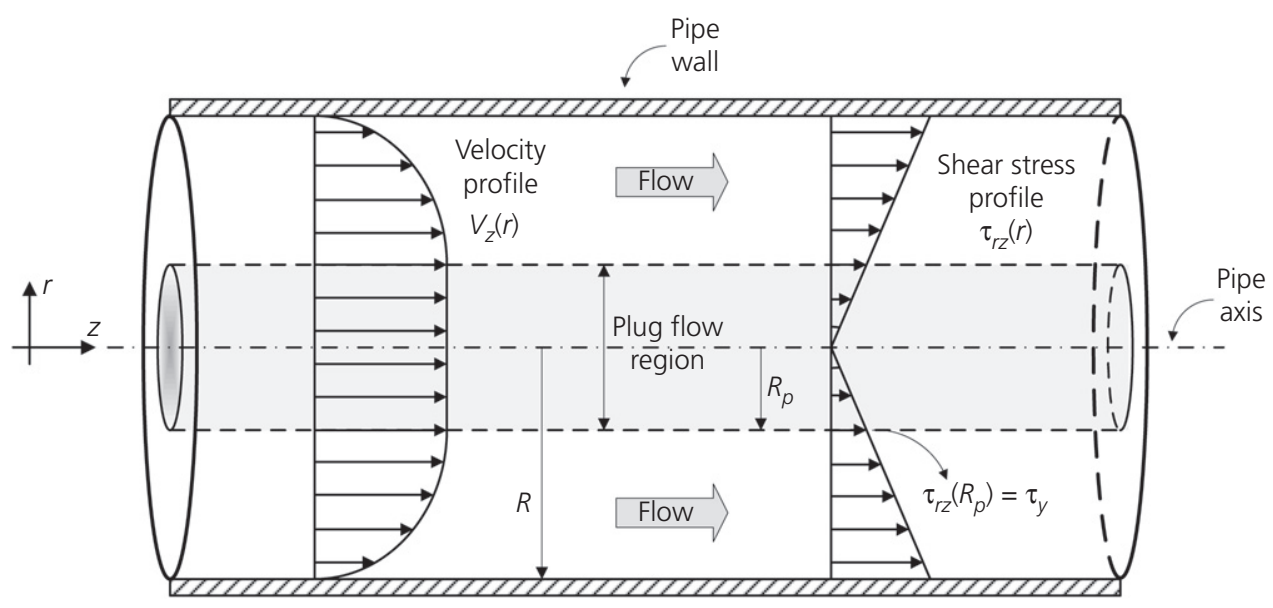

Figure 10. Velocity and stress profiles of a viscoplastic fluid in a cylindrical pipe of radius $R$

On the other hand, a velocity gradient in the region $R_{\mathrm{p}}<r<R$ develops from zero velocity at $r=R$ to the constant velocity value observed in the annular region (Figure 10).

To obtain the velocity profile, the modified Bingham model was used

9. $\tau_{r z}=\tau_{\mathrm{y}}+\eta_{\mathrm{p}}\left(-\frac{\mathrm{d} V_{z}}{\mathrm{~d} r}\right)+c\left(-\frac{\mathrm{d} V_{z}}{\mathrm{~d} r}\right)^{2}, \quad \tau_{r z}>\tau_{\mathrm{y}}$

where $-\mathrm{d} V_{z} / \mathrm{d} r$ is the shear rate. Substituting Equation 5 in Equation 9 and integrating using the non-slipping boundary condition $\left(V_{z}=0\right.$ at $\left.r=R\right)$ yields

10.

$$
\begin{aligned}
V_{z}(r)= & \frac{1}{6 c^{2} P_{l}}\left[3 c \eta_{\mathrm{p}} P_{l}(x-R)+\left(\eta_{\mathrm{p}}^{2}+2 c P_{\ell} R-4 c \tau_{\mathrm{y}}\right)^{3 / 2}\right. \\
& \left.-\left(\eta_{\mathrm{p}}^{2}+2 c P_{l} r-4 c \tau_{\mathrm{y}}\right)^{3 / 2}\right], \quad R_{\mathrm{p}}<r<R
\end{aligned}
$$

where $P_{l}=(-\Delta p / l)$ stands for the reduced pressure gradient. The velocity of the cylindrical solid body $\left(V_{\mathrm{p}}\right)$ is obtained substituting $r=R_{\mathrm{p}}$ into Equation 10

11.

$$
\begin{aligned}
V_{\mathrm{p}}= & \frac{1}{6 c^{2} P_{l}}\left[3 c \eta_{\mathrm{p}} P_{l}\left(R_{\mathrm{p}}-R\right)\right. \\
& \left.+\left(\eta_{\mathrm{p}}^{2}+2 c P_{l} R-4 c \tau_{\mathrm{y}}\right)^{3 / 2}-n^{3}\right], \quad r<R_{\mathrm{p}}
\end{aligned}
$$

The volumetric flow rate $(Q)$ is then calculated solving the integral

12. $Q=\int_{0}^{R} 2 \pi r V \mathrm{~d} r=\int_{0}^{R_{\mathrm{p}}} 2 \pi r V_{\mathrm{p}} \mathrm{d} r+\int_{R_{\mathrm{p}}}^{R} 2 \pi r V_{z} \mathrm{~d} r$

Solving Equation 12, $Q$ is obtained as a function of $\tau_{\mathrm{y}}, c$, $\eta_{\mathrm{p}}, R, \Delta P$ and $l$ 
13.

$$
\begin{aligned}
& Q=Q\left(\tau_{\mathrm{y}}, c, \eta_{\mathrm{p}}, R, \Delta P, l\right) \\
& =\frac{\pi R_{\mathrm{p}}^{2}}{12 c^{2} \tau_{\mathrm{y}}}\left[-\eta_{\mathrm{p}}^{3} R_{\mathrm{p}}+R_{\mathrm{p}}\left(\eta_{\mathrm{p}}^{2}+\frac{4 c \tau_{\mathrm{y}} R}{R_{\mathrm{p}}}-4 c \tau_{\mathrm{y}}\right)^{3 / 2}-6 c \eta_{\mathrm{p}} R \tau_{\mathrm{y}}+6 c \eta_{\mathrm{p}} R_{\mathrm{p}} \tau_{\mathrm{y}}\right]+\frac{\pi R_{\mathrm{p}}^{2}\left[\eta_{\mathrm{p}}^{2}+\left(4 c \tau_{\mathrm{y}} R / R_{\mathrm{p}}\right)-4 c \tau_{\mathrm{y}}\right]^{2}}{6720 c^{4} \tau_{\mathrm{y}}} \\
& \times\left[35 \eta_{\mathrm{p}}^{3} R_{\mathrm{p}}-27 \sqrt{\eta_{\mathrm{p}}^{2}+\frac{4 c \tau_{\mathrm{y}} R}{R_{\mathrm{p}}}-4 c \tau_{\mathrm{y}}} \eta_{\mathrm{p}}^{2} R_{\mathrm{p}}-35 c \eta_{\mathrm{p}}\left(4 R_{\mathrm{p}} \tau_{\mathrm{y}}+2 R \tau_{\mathrm{y}}\right)+6 c \sqrt{\eta_{\mathrm{p}}^{2}+\frac{4 c \tau_{\mathrm{y}} R}{R_{\mathrm{p}}}-4 c \tau_{\mathrm{y}}}\left(18 R_{\mathrm{p}} \tau_{\mathrm{y}}+10 R \tau_{\mathrm{y}}\right)\right] \\
& -\frac{\pi R_{\mathrm{p}}^{3} \eta_{\mathrm{p}}^{2}}{6720 c^{4} \tau_{\mathrm{y}}}\left[35 \eta_{\mathrm{p}}^{5}-420 c \eta_{\mathrm{p}}^{3} \tau_{\mathrm{y}}+\frac{210 c \eta_{\mathrm{p}}^{3} R \tau_{\mathrm{y}}}{R p}-1680 c^{2} \eta_{\mathrm{p}} R \tau_{\mathrm{y}}^{2}+1680 c^{2} \eta_{\mathrm{p}} \tau_{\mathrm{y}}^{2}+\eta_{\mathrm{p}}\left(8 \eta_{\mathrm{p}}^{4}-112 c \eta_{\mathrm{p}}^{2} \tau_{\mathrm{y}}+48 \tau_{\mathrm{y}}^{2}-32 c^{2} \tau_{\mathrm{y}}^{2}\right)\right. \\
& \left.+\sqrt{\eta_{\mathrm{p}}^{2}+\frac{4 c \tau_{\mathrm{y}} R}{R_{\mathrm{p}}}-4 c \tau_{\mathrm{y}}}\left(410 c \eta_{\mathrm{p}}^{2} \tau_{\mathrm{y}}-35 \eta_{\mathrm{p}}^{4}-\frac{140 c \eta_{\mathrm{p}}^{2} R \tau_{\mathrm{y}}}{R_{\mathrm{p}}}-1120 c^{2} \tau_{\mathrm{y}}^{2}+\frac{1120 c^{2} R \tau_{\mathrm{y}}^{2}}{R_{\mathrm{p}}}\right)\right]
\end{aligned}
$$

Table 5. Hydraulic power needed to pump each commercial VPC paste

\begin{tabular}{|ll|}
\hline VPC & $\boldsymbol{P}_{\mathbf{h}}: \mathbf{W}$ \\
\hline Armaduro & $358 \cdot 2$ \\
Selvalegre & $436 \cdot 8$ \\
Campeón & $465 \cdot 6$ \\
\hline
\end{tabular}

The equation for the hydraulic power $\left(P_{\mathrm{h}}\right)$ of a positive displacement pump used for concrete applications is (Karassik et al., 2001)

$$
\text { 14. } P_{\mathrm{h}}=\frac{Q \Delta P}{E_{\mathrm{m}}}
$$

where the hydraulic power is measured in watts (W), the pressure difference between suction and discharge is measured in pascals $(\mathrm{Pa})$ and $E_{\mathrm{m}}$ is the pump efficiency, usually assumed as $80 \%$. Solving for a specific case, the pipe radius, pipe length and volumetric flow rate were assumed to be $0.0625 \mathrm{~m}$, $30 \mathrm{~m}$ and $15 \mathrm{~m}^{3} / \mathrm{h}$, respectively. These values correspond to practical situations for cement purposes (Chen and Richard Liew, 2002; Merrit and Ricketts, 2001) and to concrete pump manufacturers' catalogues.

Substituting the modified Bingham model parameters and the pipe length and radius in Equation 13, the volumetric flow rate is obtained as a complex function of $R_{\mathrm{p}}$. Using an iterative method, the pressure difference $\Delta P$ was obtained and substituted into Equation 14 to obtain the hydraulic pressure needed to pump each VPC. The results in Table 5 show that more hydraulic power is needed to pump VPC with a higher $\mathrm{VP}+\mathrm{PP}$ content.

\section{REFERENCES}

Abdelkader B, El-Hadj K and Karim E (2010) Efficiency of granulated blast furnace slag replacement of cement according to the equivalent binder concept. Cement \& Concrete Composites 32(3): 226-231.

ASTM (2015) C 31: Standard practice for making and curing concrete test specimens in the field. ASTM International, West Conshohocken, PA, USA.

Banfill PFG (2006) Rheology of fresh cement and concrete. In Rheology Reviews, The British Society of Rheology, UK, pp. 61-130.

Barnes HA and Carnali JO (1990) The vane-in-cup rheometer as a novel rheometer geometry for shear thinning and thixotropic materials. Journal of Rheology 34(6): 841-866.

Bernal SA, Mejía de Gutiérrez R, Pedraza AL et al. (2011) Effect of binder content on the performance of alkali-activated slag concretes. Cement and Concrete Research 41(1): 1-8.

Bilodeau A and Malhotra VM (2000) High volume fly ash system: concrete solution for sustainable development. ACI Materials Journal 97(1): 41-48.

Bui DD, Hu J and Stroeven P (2005) Particle size effect on the strength of rice husk ash blended gap-graded Portland cement concrete. Cement \& Concrete Composites 27(3): 357-366.

Chhabra RP and Richardson JF (1999) Non-Newtonian Flow: Fundamentals and Engineering Applications Butterworth-Heinemann, Oxford, UK.

Chatveera B and Lertwattanaruk P (2009) Evaluation of sulfate resistance of cement mortars containing black rice husk ash. Journal of Environmental Management 90(3): 1435-1441.

Chatveera B and Lertwattanaruk P (2011) Durability of conventional concretes containing black rice husk ash. Journal of Environmental Management 92(1): 59-66.

Chen WF and Richard Liew JY (2002) The Civil Engineering Handbook, 2nd edn. CRC Press, Boca Raton, FL, USA.

Dellinghausen LM, Gastaldini ALG, Vanzin FJ and Veiga KK (2012) Total shrinkage, oxygen permeability, and chloride ion penetration in concrete made with white Portland cement and blast-furnace slag. Construction and Building Materials 37(1): 652-659.

Farris RJ (1968) Prediction of the viscosity of multi modal suspensions from viscosity data. Transactions of the Society of Rheology 12(2) $281-301$.

Ferraris C (2005) Concrete rheology: what is it and why do we need it. Proceedings of the 1st International Symposium on Design, Performance and Use of SCC, China Changsha, Hunan, China (Yu Z, Shi C, Khayat KH and Xie Y (eds)). RILEM Publications, Paris, France, pp. 229-236.

Ferraris CF and Gaidis JM (1992) Connection between the rheology of concrete and rheology of cement paste. ACI Materials Journal 89(4): 388-393. 
Feys D, Verhoeven R and De Schutter G (2007) Evaluation of time independent rheological models applicable to fresh self-compacting concrete. Applied Rheology 17(5): 56244.

Flatt RJ (2004) Towards a prediction of superplasticized concrete rheology. Materials and Structures 37(5): 289-300.

Giaccio G, Rodríguez de Sensale G and Zerbino R (2007) Failure mechanism of normal and high-strength concrete with rice-husk ash. Cement \& Concrete Composites 29(7): 566-574.

Han D and Ferron RD (2015) Effect of mixing method on microstructure and rheology of cement paste. Construction and Building Materials 93(1): 278-288.

Horton R (2001) Factor ten emission reductions: the key to sustainable development and economic prosperity for the cement and concrete industry. In Proceedings of the 3rd Canmet/ACI International. Sustainable Development of Cement and Concrete (Malhotra VM (ed.)). American Concrete Institute, Farmington Hills, MI, USA, pp. 1-14.

Hossain KMA (2003) Blended cement using volcanic ash and pumice. Cement and Concrete Research 33(10): 1601-1605.

Hossain KMA (2004) Properties of volcanic pumice based cement and lightweight concrete. Cement and Concrete Research 34(2): 283-291.

Hossain KMA (2005) Chloride induced corrosion of reinforcement in volcanic ash and pumice based blended concrete. Cement \& Concrete Composites 27(3): 381-390.

Hossain KMA, Ahmed S and Lachemi M (2011) Lightweight concrete incorporating pumice based blended cement and aggregate: mechanical and durability characteristics. Construction and Building Materials 25(3): 1186-1195.

Hu C and De Larrard F (1996) The rheology of fresh high-performance concrete. Cement and Concrete Research 26(2): 283-294.

Kabay N, Tufekci MM, Kizilkanat AB and Oktay D (2015) Properties of concrete with pumice powder and fly ash as cement replacement materials. Construction and Building Materials 85(1): $1-8$.

Karassik IJ, Messina JP, Cooper P and Heald CC (2001) Pump Handbook, 3rd edn. McGraw-Hill, New York, NY, USA.

Khatib JM (2008) Metakaolin concrete at a low water to binder ratio. Construction and Building Materials 22(8): 1691-1700.

Langan BW, Weng K and Ward MA (2002) Effect of silica fume and fly ash on heat of hydration of Portland cement. Cement and Concrete Research 32(7): 1045-1051.

Macosko CW (1994) Rheology. Principles, Measurements and Applications. Wiley-VCH, New York, NY, USA

Malhotra VM (2010) Global warming, and role of supplementary cementing materials and superplasticisers in reducing greenhouse gas emissions from the manufacturing of Portland cement. International Journal of Structural Engineering 1(2): 116-130.

Masoero E, Delgado E, Pellenq RJM, Ulm FJ and Yip S (2012) Nanostructure and nanomechanics of cement: polydisperse colloidal packing. Physics Review Letters 109(15): 155503.

McCarthy MJ and Dhir RK (1999) Towards maximising the use of fly ash as a binder. Fuel 78(2): 121-132.

Meinhold U, Mellmann G and Maultzsch M (2001)

Performance of high-grade concrete with full substitution of aggregates by recycled concrete. In Proceedings of the 3rd Canmet/ACI International. Sustainable Development of Cement and Concrete (Malhotra VM (ed.)). American Concrete Institute, Farmington Hills, MI, USA, pp. 85-96.

Memon SA, Shaikh MA and Akbar H (2011) Utilization of rice husk ash as viscosity modifying agent in self-compacting concrete. Construction and Building Materials 25(2): 1044-1048.
Merrit FS and Ricketts JT (2001) Building Design and Construction Handbook, 5th edn. McGraw-Hill, New York, NY, USA.

NTE INEN (2011) 490: Cementos hidráulicos compuestos. Instituto Ecuatoriano de Normalización, Quito, Ecuador (in Spanish).

Paya J, Borrachero MV, Monzo J, Peris-Mora E and Amahjour F (2001) Enhanced conductivity measurement techniques for evaluation of fly ash pozzolanic activity. Cement and Concrete Research 31(1): $41-49$.

Popovic K (2001) Reducing $\mathrm{CO}_{2}$ emission into the atmosphere-achievements and experience of creation cement industry. In Proceedings of the 3rd Canmet/ACI International. Sustainable Development of Cement and Concrete (Malhotra VM (ed.)). American Concrete Institute, Farmington Hills, MI, USA, pp. 73-84.

Ramezanianpour AA (2014) Cement Replacement Materials. Springer Geochemistry/Mineralogy. Springer, Heidelberg, Germany.

Ramezanianpour AA, Ghiasvand E, Nickseresht I, Mahdikhani M and Moodi F (2009) Influence of various amounts of limestone powder on performance of Portland limestone cement concretes. Cement \& Concrete Composites 31(10): 715-720.

Roussel N (2006) A thixotropy model for fresh fluid concretes: theory, validation and applications. Cement and Concrete Research 36(10): 1797-1806.

Roussel N, Ovarlez G, Garrault S and Brumaud C (2012) The origins of thixotropy of fresh cement pastes. Cement and Concrete Research 42(1): 148-157.

Rubio-Hernández FJ, Cerezo-Aizpún I and Velázquez-Navarro JF (2011) Mineral additives geometry influence in cement pastes flow. Advances in Cement Research 23(2): 55-60, http://dx.doi.org/ 10.1680/adcr.9.00009

Rubio-Hernández FJ, Morales-Alcalde JM and Gómez-Merino AI (2013a) Limestone filler/cement ratio effect on the flow behaviour of a SCC cement paste. Advances in Cement Research 25(5): 262-272, http://dx.doi.org/10.1680/adcr.12.00027

Rubio-Hernández FJ, Velázquez-Navarro JF and Ordóñez-Belloc LM (2013b) Rheology of concrete: a study case based upon the use of the concrete equivalent mortar. Materials and Structures 46(4): $587-605$.

Safiuddin M, West JS and Soudki KA (2012) Properties of freshly mixed self-consolidating concretes incorporating rice husk ash as a supplementary cementing material. Construction and Building Materials 30(1): 833-842.

Schwartzentruber A and Catherine C (2000) Method of the concrete equivalent mortar (CEM). A new tool to design concrete containing admixture. Materials and Structures 33(8): 475-482.

Sfikas IP, Badogiannis EG and Trezos KG (2014) Rheology and mechanical characteristics of self-compacting concrete mixtures containing metakaolin. Construction and Building Materials 64(1): 121-129.

Sonebi M and Cevik A (2009) Genetic programming based formulation for fresh and hardened properties of self-compacting concrete containing pulverised fuel ash. Construction and Building Materials 23(7): 2614-2622.

Struble L and Sun GK (1995) Viscosity of Portland cement paste as a function of concentration. Advanced Cement Based Materials 2(2): 62-69.

Sujata K and Jennings HM (1992) Formation of a protective layer during the hydration of cement. Journal of the American Ceramic Society 75(6): 1669-1673.

Toutou Z and Roussel N (2006) Multi scale experimental study of concrete rheology: from water scale to gravel scale. Materials and Structures 39(2): 189-199. 
Uchikawa H (2000) Sustainable development of the cement and concrete industry. In Concrete Technology for a Sustainable Development in the 21st Century (Odd EG and Koji S (eds)). E \& FN Spon, New York, NY, USA.

Wallevik OH and Gjorv OE (1990) Development of a coaxial cylinder viscometer for fresh concrete, in 'properties of fresh concrete'. Proceedings of the Rilem Colloquium. Chapman \& Hall, London, UK, pp. 213-224.
Yahia A and Khayat KH (2001) Analytical models for estimating yield stress of high-performance pseudoplastic grouts. Cement and Concrete Research 31(5): 731-738.

Zerbino R, Giaccio G, Batic OR and Isaia GC (2012) Alkali-silica reaction in mortars and concretes incorporating natural rice husk ash. Construction and Building Materials 36(1): 796-806. Zhen-Shuang W (2011) Influence of fly ash on the mechanical properties of frame concrete. Sustainable Cities and Society 1(3): 164-169.

\section{How can you contribute?}

To discuss this paper, please submit up to 500 words to the editor at journals@ice.org.uk. Your contribution will be forwarded to the author(s) for a reply and, if considered appropriate by the editorial board, it will be published as a discussion in a future issue of the journal. 